\title{
Multiple inferior vena cava aneurysms mimic a retroperitoneal tumor: a case report
}

\author{
Yuzhi Zuo, Zhenyu Zhang, Bingbing Shi, Zhigang Ji and Zhongming Huang*
}

\begin{abstract}
Background: Inferior vena cava (IVC) aneurysms are extremely rare with variable clinical manifestations. Patients are usually asymptomatic or present with complications of thrombosis and rupture. To date, there have been only a few reports of the condition in the literature, and diagnosis of IVC aneurysms may be difficult.

Case presentation: A 33-year-old male patient presented to hospital because of a retroperitoneal mass found by computerized tomography during a health examination. He was asymptomatic, and post medical history and physical examination were unremarkable. Laboratory tests including tests for paraganglioma were all negative. Contrast-enhanced computed tomography scan revealed a stenosis of IVC in the suprarenal segment and two retroperitoneal mass on the right side of IVC. The larger one is about $3 \mathrm{~cm}$ in diameter and the smaller one is about $1 \mathrm{~cm}$ in diameter, which was considered as a retroperitoneal tumor with an enlarged lymph node. However, two IVC diverticular aneurysms were confirmed during the retroperitoneal laparoscopic exploration. The larger aneurysm was resected from the IVC successfully. Since the smaller aneurysm was about $1 \mathrm{~cm}$ in diameter without thrombosis, we did not resect it during surgery. The patient recovered well from surgery and discharged from our department successfully.

Conclusions: This is the first report of multiple IVC aneurysms. Because of the extremely low prevalence of IVC diverticular aneurysm, it may be misdiagnosed as other disease. Due to the high rate of thrombosis, surgical treatment especially retroperitoneal laparoscopy is recommended for small diverticular aneurysms.
\end{abstract}

Keywords: Inferior vena cava, Diverticular aneurysm, Retroperitoneal laparoscopy, Case report

\section{Background}

Aneurysms are local vascular dilatations that develop when part of the vascular wall weakens, which mostly occur in arterial system. Although venous aneurysms can also occur throughout the body [1], they are relatively uncommon, and inferior vena cava (IVC) aneurysms are extremely rare. The first case of an IVC aneurysm was reported in 1972 by Conn [2]. To date, there have been only a few reports of the condition in

\footnotetext{
* Correspondence: zhmhuang@hotmail.com

Department of Urology, Peking Union Medical College Hospital, Peking Union Medical College and Chinese Academy of Medical Sciences, No.1 Shuaifuyuan, Beijing 100730, P.R. China
}

the literature, and diagnosis of IVC aneurysms may be difficult. Here, we describe a case involving multiple IVC malformations, including aneurysms that mimicked a retroperitoneal tumor with an enlarged lymph node.

\section{Case presentation}

A 33-year-old Chinese male patient presented to Urology Department because of a retroperitoneal mass that was incidentally found by computerized tomography (CT) during a health examination. He was asymptomatic and had no abdominal or back pain, episodic hypertension, palpitation, or lower limb edema. Post medical history and physical examination were unremarkable.

(c) The Author(s). 2020 Open Access This article is licensed under a Creative Commons Attribution 4.0 International License, which permits use, sharing, adaptation, distribution and reproduction in any medium or format, as long as you give appropriate credit to the original author(s) and the source, provide a link to the Creative Commons licence, and indicate if changes were made. The images or other third party material in this article are included in the article's Creative Commons licence, unless indicated otherwise in a credit line to the material. If material is not included in the article's Creative Commons licence and your intended use is not permitted by statutory regulation or exceeds the permitted use, you will need to obtain permission directly from the copyright holder. To view a copy of this licence, visit http://creativecommons.org/licenses/by/4.0/. The Creative Commons Public Domain Dedication waiver (http://creativecommons.org/publicdomain/zero/1.0/) applies to the data made available in this article, unless otherwise stated in a credit line to the data. 
Laboratory tests including complete blood count, liver and renal function and D-Dimer were normal. Tests for paraganglioma such as 24-h urinary catecholamine and somatostatin receptor imaging were negative. Contrastenhanced CT scan revealed a stenosis of IVC in the suprarenal segment (Fig. 1a), a $34 \mathrm{~mm} \times 30 \mathrm{~mm} \times 33 \mathrm{~mm}$ retroperitoneal mass on the right side of the infrarenal IVC (Fig. 1a and b) and a small mass about $10 \mathrm{~mm}$ in diameter in the retroperitoneal area that was considered an enlarged lymph node (Fig. 1c). No thrombosis was found in the IVC. Therefore, a diagnosis of retroperitoneal tumor with possible lymph node metastasis was considered.

To further confirm our diagnosis, a retroperitoneal laparoscopic exploration was performed. During the surgery, we found that both mass were diverticular aneurysms of IVC (Fig. 2a). There was a very narrow neck between the larger aneurysm and IVC (Fig. 2b). A hemo-lok clamp was applied on the neck of aneurysm (Fig. 2c), and the aneurysm was resected from the IVC successfully. Since the smaller aneurysm was about $1 \mathrm{~cm}$ in diameter without thrombosis, we did not resect it during surgery. However, the stenosis of IVC may cause venous hypertension which can be a risk factor for aneurysms progression. Therefore, we referred the patient to Vascular Surgery Department for pressure gradient test across the suprarenal IVC to determine the following therapy. They suggested to monitor the size of aneurysm annually to determine further treatment. The patient recovered well from surgery and discharged from our department successfully. The pathology shows vascular wall tissue with a lot fibrous tissue, which is consistent with the diagnosis of IVC aneurysm. However, there is no intact vascular wall identified.

\section{Discussion and conclusions}

Our patient had multiple IVC malformations, including two IVC aneurysms. IVC aneurysms are extremely rare with variable clinical manifestations. They may be discovered incidentally in asymptomatic patients, as it was in our case, or may present with complications, such as leg swelling, pulmonary embolism and retroperitoneal mass related effects, like abdominal/low back pain, hydronephrosis and bowel obstruction [3-5]. Because the symptoms are non-specific, imaging tests like ultrasonography, contrast-enhanced CT, magnetic resonance imaging and cavography play a vital role in the diagnosis of IVC aneurysms [6]. However, some IVC aneurysms could be confused with retroperitoneal tumors, such as renal carcinoma, sarcomas, enlarged lymph nodes, neurogenic tumors and primary IVC tumors [7-9], especially when the lumen of the aneurysm is completely thrombosed [8]. Therefore, comprehensive consideration of various imaging tests results can increase the accuracy
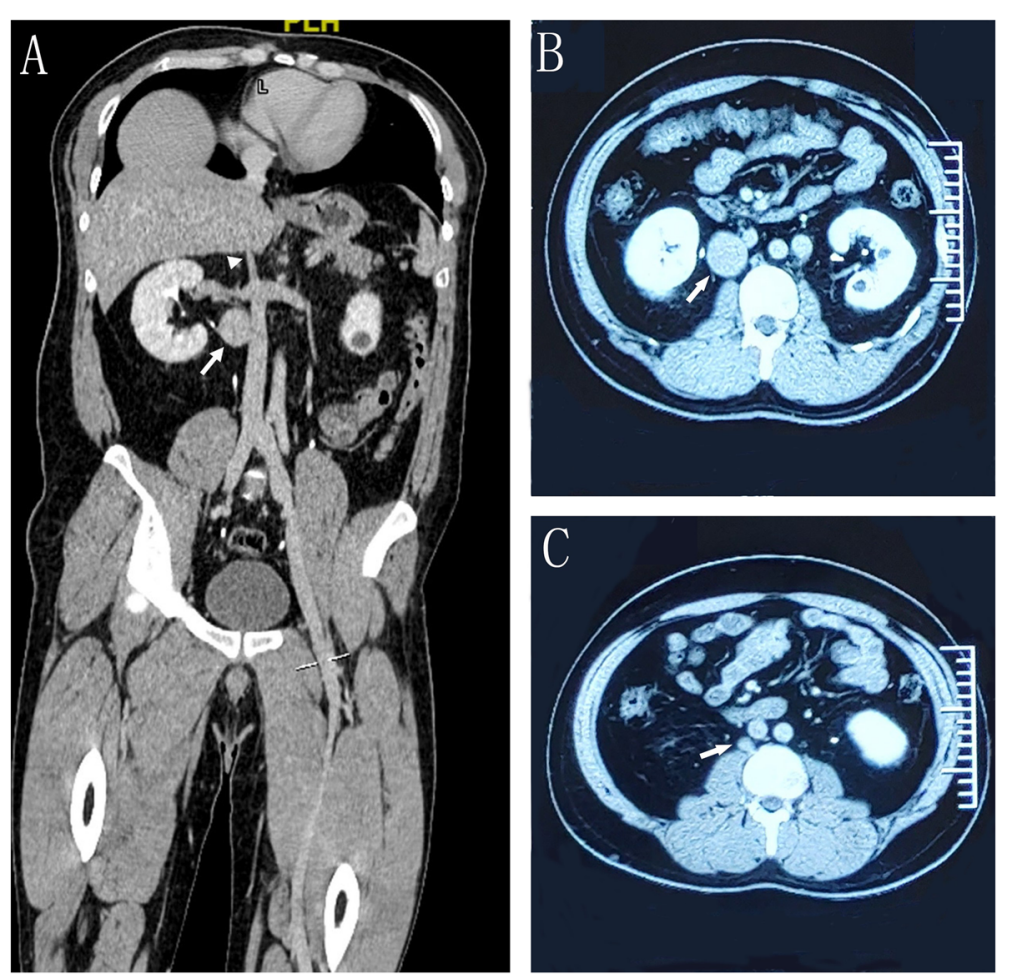

Fig. 1 Contrast-enhanced CT imaging. a Coronal view showing the stenosis of IVC (arrowhead) and a retroperitoneal mass on the right side of the infrarenal IVC (long arrow). b and c Axial view showing the two retroperitoneal mass (long arrow) 

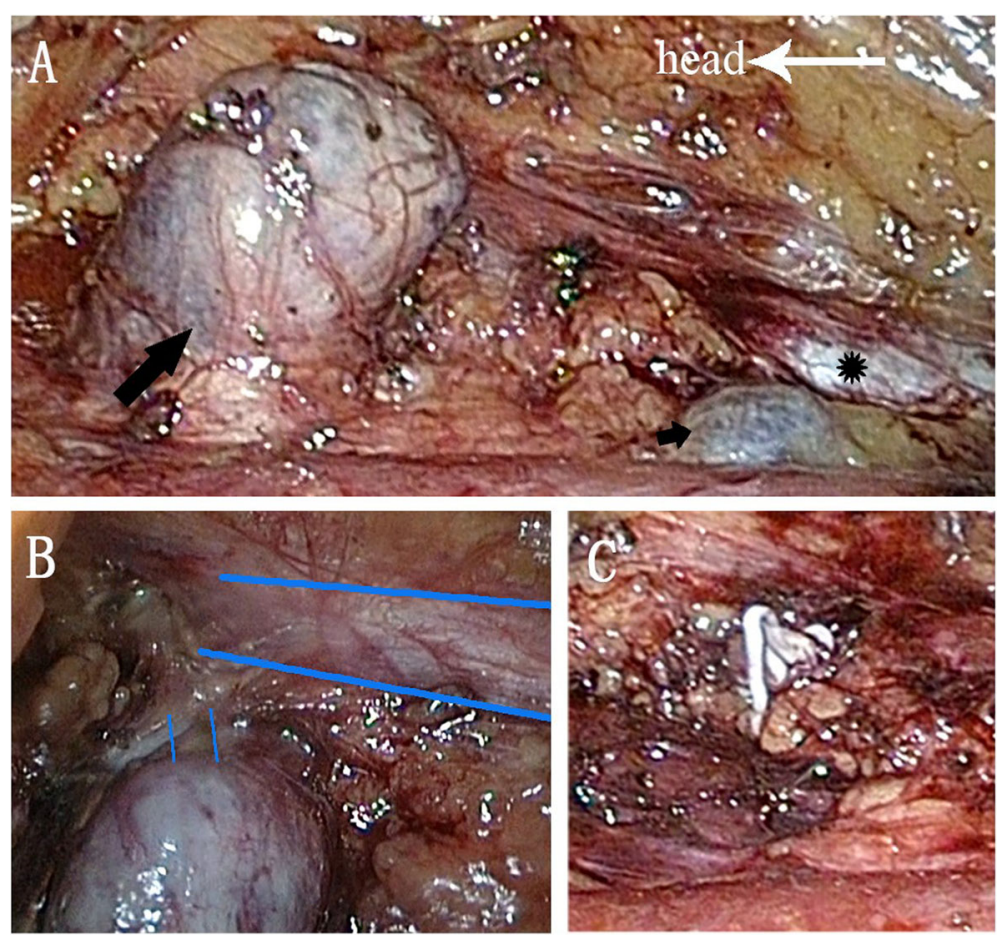

Fig. 2 Intra-operative photographs. a IVC (black star) and two aneurysms (black long arrow and short arrow). b A narrow neck between the larger aneurysm and IVC (blue thick lines showing edges of IVC and thin lines showing the neck of the aneurysm). $\mathbf{c}$ Hem-o-lok in the neck of aneurysm after resection

of diagnosis. Cavography or surgical exploration is recommended when an IVC aneurysm is highly suspected. Biopsy should be more carefully chosen when the nature of the mass is unclear.

Pathological studies have revealed that IVC aneurysms are composed of all three layers of the normal venous wall with thinning elastic and muscular layers [10]. However, the etiology of IVC aneurysms is still unclear. Trauma, injury, inflammation, longstanding venous hypertension secondary to heart failure, cardiomyopathy, tricuspid valve lesions, constrictive pericarditis and stenosis of IVC are all risk factors of IVC aneurysms. As many cases are diagnosed in childhood, congenital defects like embryological venous malformations are considered the most common cause [11-15].

Embryological development of IVC is complex. Through complex sequential processes of development, anastomosis and regression of three parallel veins (the postcardinal, subcardinal and supracardinal veins), the mature IVC forms [16, 17]. The normal IVC is composed of four segments, including the infrarenal, renal, suprarenal and hepatic IVC, which are derived from supracardinal veins, subcardinal-supracardinal vein anastomoses, subcardinal veins and subcardinal-hepatic vein anastomoses, respectively $[18,19]$. Our patient presented with no risk factors, and multiple IVC malformations were observed, indicating that an embryological development anomaly may be the cause of his condition.

In the literature, there are two classification systems for IVC aneurysms (Table 1). The Thompson and Lindenauer classification includes three types based on the etiology of aneurysm [20]. However, application of this classification is limited, since the etiology of aneurysm is unclear in most cases. Gradman and Steinberg classified IVC aneurysms into four types depending on the relation to the hepatic vein and the resultant obstruction [21]. Type I IVC aneurysms were most common, followed by type III. Type IV IVC aneurysms were rare [12]. This classification has more utility in clinic and is used in our article.

Table 1 IVC aneurysm classification system

\begin{tabular}{lll}
\hline & Gradman and Steinberg classification & Thompson and Lindenauer classification \\
\hline Type I & Aneurysms of the suprahepatic IVC without venous obstruction & Congenital aneurysm \\
Type II & Aneurysms associated with interruption of the IVC above or below the hepatic vein & Acquired aneurysm \\
Type III & Aneurysms confined to the infrarenal IVC without associated venous anomaly & Aneurysm secondary to arteriovenous fistula \\
Type IV & Miscellaneous & \\
\hline
\end{tabular}


Table 2 Reported diverticular IVC aneurysms

\begin{tabular}{|c|c|c|c|c|c|c|c|c|}
\hline Author & Year & $\begin{array}{l}\text { Age } \\
\text { (year) }\end{array}$ & Gender & Presentation & Location & Thrombosis & Treatment & Outcome \\
\hline $\begin{array}{l}\text { Hasan, et al. } \\
{[16]}\end{array}$ & 1992 & 59 & Male & Abdominal pain & Infrarenal & No & Open surgical resection & Good \\
\hline $\begin{array}{l}\text { Levesque, } \\
\text { et al. [27] }\end{array}$ & 1993 & 70 & Male & Asymptomatic & Infrarenal & Yes & Monitoring & $\begin{array}{l}\text { No changes in } \\
\text { thrombosis or aneurysm } \\
\text { size }\end{array}$ \\
\hline $\begin{array}{l}\text { Gradman, } \\
\text { et al. [21] }\end{array}$ & 1993 & 45 & Male & $\begin{array}{l}\text { Back and chest pain, swelling of } \\
\text { left lower extremity }\end{array}$ & Infrarenal & Yes & Open surgical resection & Good \\
\hline $\begin{array}{l}\text { Davidovic, } \\
\text { et al. [3] }\end{array}$ & 2008 & 27 & Male & $\begin{array}{l}\text { Abdominal pain and swelling of } \\
\text { bilateral lower extremities }\end{array}$ & Infrarenal & Yes & Open surgical resection & Good \\
\hline $\begin{array}{l}\text { Deshpande, } \\
\text { et al. [28] }\end{array}$ & 2010 & 40 & Male & $\begin{array}{l}\text { Bilateral lower extremity swelling } \\
\text { and pain }\end{array}$ & Infrarenal & Yes & $\begin{array}{l}\text { Open surgical resection } \\
\text { and anticoagulation }\end{array}$ & Good \\
\hline $\begin{array}{l}\text { Weber, et al. } \\
\text { [29] }\end{array}$ & 2011 & 13 & Male & $\begin{array}{l}\text { Left lower extremity swelling and } \\
\text { pain }\end{array}$ & Infrarenal & Yes & $\begin{array}{l}\text { Open surgical resection } \\
\text { and anticoagulation }\end{array}$ & Good \\
\hline $\begin{array}{l}\text { Tadayon, } \\
\text { et al. [22] }\end{array}$ & 2019 & 22 & Male & Abdominal pain & Infrarenal & No & Open surgical resection & Good \\
\hline $\begin{array}{l}\text { Ladurner, } \\
\text { et al. [30] }\end{array}$ & 2019 & 23 & Male & NM & Infrarenal & Yes & Anticoagulation & NM \\
\hline
\end{tabular}

NM Not mentioned

However, both of the classification systems have limited guidance for treatment and prognosis.

Due to potential life-threatening morbidities, such as thromboembolic events and rupture, treatment of IVC aneurysms is recommended [3, 12, 22]. However, there is no consensus on patient management. In some literature reviews, surgical treatment such as resection and reconstruction is recommended for types II-IV or symptomatic patients [3, 11, 12]. Endovascular techniques were also recently reported in the treatment of IVC aneurysm. Michel et al. [23] successfully embolized a congenital large saccular aneurysm of the infrarenal IVC in a 2.5-year-old male with coils and an Amplatzer vascular plug device. Falkowski et al. [24] implanted a custom-made stent-graft in an infrarenal IVC aneurysm to exclude it from the circulation completely. Walsh et al. [25] performed balloon angioplasty to improve the congenital stenosis of IVC in a type II aneurysm, and aneurysm size was decreased during the follow-up. Asymptomatic type I IVC aneurysm can be managed conservatively by regularly monitoring aneurysm size and the development of any complications [26]. Medical management can include anticoagulation and IVC filter placement in patients with thrombosis.

In our case, it was difficult to classify the IVC aneurysms accurately. There were two infrarenal IVC aneurysm and stenosis of suprarenal IVC. It was unclear whether the aneurysm was associated with the stenosis of IVC. In our opinion, there was no obvious dilation of the distal IVC, and the aneurysms were relatively far from the stenosis. Therefore, the infrarenal IVC aneurysms were probably not associated with the stenosis, and thus, are type III IVC aneurysms. IVC aneurysms can be saccular, fusiform or diverticular. The diverticular type is rare, and to date there have been only eight cases reported in the literature [3, 16, 21, 22, 27-30] (Table 2). All reported patients were male, and all aneurysms were located at the infrarenal IVC segment, which is different from the IVC aneurysm entity. Therefore, diverticular IVC aneurysms may be a special type of IVC aneurysm, and it is probably caused by the incomplete regression of supracardinal vein branches. Due to the high rate of thrombosis associated with diverticular IVC aneurysms, surgical treatment is recommended. Compared to open surgical operation, retroperitoneal laparoscopy is less invasive with a shorter in-hospital duration and less blood loss, and it is especially suitable for treating small aneurysm. Endovascular treatment is an alternative method for patients without thrombosis.

Table 2. Reported diverticular IVC aneurysms (in the end of the file).

IVC aneurysms are extremely rare, and this is the first report of multiple IVC diverticular aneurysms. It should be a differential diagnosis in the evaluation of retroperitoneal tumors. In addition, IVC diverticular aneurysms may be a special type. Due to the high rate of thrombosis, surgical treatment is recommended and retroperitoneal laparoscopy is suitable for small aneurysms.

\section{Abbreviations}

IVC: Inferior vena cava; CT: Computerized tomography

\section{Acknowledgements}

We thank the nurses for taking good care of our patient, which enhanced his discharge successfully.

\section{Authors' contributions}

$\mathrm{ZH}, \mathrm{ZZ}$ and BS performed the surgery and collected the patient clinical data. $Y Z$ wrote the manuscript and ZJ was a major contributor in manuscript revision. All authors read and approved the final manuscript. 


\section{Funding}

There is no funding in this study.

\section{Availability of data and materials}

All data generated or analyzed during this study are included in this published article.

\section{Ethics approval and consent to participate}

The Ethics Committee of Peking Union Medical College Hospital, Peking Union Medical College and Chinese Academy of Medical Sciences approved this study.

\section{Consent for publication}

Written informed consent was obtained from the patient for publication of this Case report and any accompanying images. A copy of the written consent is available for review by the Editor of this journal.

\section{Competing interests}

The authors declare that they have no competing interests.

Received: 1 June 2020 Accepted: 21 August 2020

Published online: 01 September 2020

\section{References}

1. French JR, Moncrieff NJ, Englund R, Hanel KC. Thrombotic complications of venous aneurysms. ANZ J Surg. 2003;73(6):384-6.

2. Conn HO, Ramsby GR. Aneurysm of the inferior vena cava after portacaval anastomosis. Surgery. 1972;71(6):828-33.

3. Davidovic L, Dragas M, Bozic V, Takac D. Aneurysm of the inferior vena cava: case report and review of the literature. Phlebology. 2008;23(4):184-8.

4. Jegananthan R, Reid JA, Hannon RJ. Aneurysm of the inferior vena cava. Surgeon. 2003;1(3):164-5.

5. Debing E, Vanhulle A, van Tussenbroek F, von Kemp K, Van den Brande P. Idiopathic aneurysm of the inferior vena cava as a cause of massive penile bleeding. Eur J Vasc Endovasc Surg. 1998;15(4):365-8.

6. Momeni M, Momeni F. Ruptured inferior vena cava aneurysm in the setting of mural vascular malformation: a case report. J Clin Ultrasound. 2019;47(7): 423-5.

7. Rodríguez-González M, Castellano-Martinez A. Inferior vena cava aneurysm in children: a case report. Ann Vasc Surg. 2017;38:315.e9-315.e13.

8. Unzueta-Roch JL, García-Abós M, Sirvent-Cerdá S, de Prada I, Martínez de Azagra A, Ollero JM, et al. Inferior vena cava aneurysm in an infant presenting with a renal mass. J Pediatr Hematol Oncol. 2014:36(7):583-5.

9. de Bree E, Klaase JM, Schultze Kool LJ, van Coevorden. Aneurysm of the inferior vena cava complicated by thrombosis mimicking a retroperitoneal neoplasm. Eur J Vasc Endovasc Surg. 2000;20(3):305-7.

10. Calligaro KD, Ahmad S, Dandora R, Dougherty MJ, Savarese RP, Doerr KJ et al. Venous aneurysms: surgical indications and review of the literature. Surgery. 1995:117(1):1-6.

11. Gusani R, Shukla R, Kothari S, Bhatt R, Patel J. Inferior vena cava aneurysm presenting as deep vein thrombosis - a case report. Int J Surg Case Rep. 2016:29:123-5.

12. Montero-Baker MF, Branco BC, Leon LL Jr, Labropoulos N, Echeverria A, Mills J Sr. Management of inferior vena cava aneurysm. J Cardiovasc Surg. 2015; 56(5):769-74.

13. Makaloski V, Schmidli J. Giant symptomatic aneurysm of the inferior vena cava. Eur J Vasc Endovasc Surg. 2015;49(3):247

14. Inoue M, Sudo T, Yamaguchi M, Seo S, Miyamoto T, Misumi T, et al. Aneurysm of the inferior vena cava with thrombosis. Clin Case Rep. 2018; 6(2):402-6.

15. Wells IT, Bhatnagar R. Presumed rupture of a massive inferior vena cava aneurysm associated with right heart failure; a unique case. Clin Radiol. 2008;63(10):1181-3.

16. Hasan F, Gleeson F, Lock MR, Williams R, Grant D. Diverticulum of the inferior vena cava: a case report. J Vasc Surg. 1992;15(3):578-80.

17. Sürücü HS, Erbil KM, Tastan C, Yener N. Anomalous veins of the retroperitoneum: clinical considerations. Surg Radiol Anat. 2001;23(6):443-5.

18. Mookadam F, Rowley VB, Emani UR, Al-Harthi MS, Baxter CM, Wilansky S, et al. Aneurysmal dilatation of the inferior vena cava. Echocardiography. 2011;28(8):833-42
19. Woo K, Cook P, Saeed M, Dilley R. Inferior vena cava aneurysm. Vascular. 2009:17(5):284-9.

20. Thompson NW, Lindenauer SM. Central venous aneurysms and arteriovenous fistulas. Ann Surg. 1969;170(5):852-6.

21. Gradman WS, Steinberg F. Aneurysm of the inferior vena cava: case report and review of the literature. Ann Vasc Surg. 1993;7(4):347-53.

22. Tadayon N, Kalantar-Motamedi SM, Zarrintan S, Tayyebi A. Isolated inferior vena cava aneurysm: a case report. J Cardiovasc Thorac Res. 2019;11(1):72-4.

23. Michel $\mathrm{LL}$, Alomari Al. Embolization of a large inferior vena cava aneurysm in a child. J Vasc Interv Radiol. 2008;19(10):1509-12.

24. Falkowski A, Wiernicki I. Stent-graft implantation to treat an inferior vena cava aneurysm. J Endovasc Ther. 2013;20(5):714-7.

25. Walsh K, O'Connor D, Wilderman M, Ratnathicam A, Simonian G, Napolitano MM. Balloon angioplasty for symptomatic inferior vena cava aneurysm. J Vasc Surg Venous Lymphat Disord. 2018;6(5):661-3.

26. Le Moigne F, Jarry J, Michel P, Vitry T, Rode A. Aneurysm of the retrohepatic inferior vena cava. J Mal Vasc. 2013:38(1):58-9.

27. Levesque H, Cailleux N, Courtois H, Clavier E, Milon P, Benozio M. Idiopathic saccular aneurysm of the inferior vena cava: a new case. J Vasc Surg. 1993; 18(3):544-5.

28. Deshpande A, Sahoo S, Chaudhari P, Abhijit R. Aneurysm of the inferior vena cava: accurate preoperative diagnosis and surgical excision. ANZ J Surg. 2010;80(7-8):552-3.

29. Weber $C_{\text {, J J }}$ Jon K, Milner R. Resection and primary repair of an inferior vena cava aneurysm in a 13-year-old male. Vascular. 2011;19(4):218-22.

30. Ladurner $\mathrm{R}$, Strohaeker J, Bongers $\mathrm{M}$. The rare occurrence of an aneursym of the inferior vena cava. Dtsch Arztebl Int. 2019;116:841.

\section{Publisher's Note}

Springer Nature remains neutral with regard to jurisdictional claims in published maps and institutional affiliations.

\section{Ready to submit your research? Choose BMC and benefit from:}

- fast, convenient online submission

- thorough peer review by experienced researchers in your field

- rapid publication on acceptance

- support for research data, including large and complex data types

- gold Open Access which fosters wider collaboration and increased citations

- maximum visibility for your research: over $100 \mathrm{M}$ website views per year

At BMC, research is always in progress.

Learn more biomedcentral.com/submissions 